\title{
Nutritional Deficiencies Are Common in Patients with Transfusion-Dependent Thalassemia and Associated with Iron Overload
}

\author{
Elijah K Goldberg ${ }^{1}$, Sushrita Neogi ${ }^{1}$, Ashutosh Lal ${ }^{2}$, Annie Higa ${ }^{3}$, Ellen Fung ${ }^{1,2, *}$ \\ ${ }^{1}$ Children’s Hospital Oakland Research Institute, 5700 Martin Luther King Jr. Way, Oakland CA, 94609 \\ ${ }^{2}$ Department of Hematology, UCSF Benioff Children's Hospital Oakland, 5700 Martin Luther King Jr. Way, Oakland CA, 94609 \\ ${ }^{3}$ Clinical and Translational Sciences Institute, UCSF Benioff Children's Hospital, \\ 5700 Martin Luther King Jr. Way, Oakland CA, 94609 \\ *Corresponding author: efung@mail.cho.org
}

Received September 19, 2018; Revised November 05, 2018; Accepted November 21, 2018

\begin{abstract}
Patients with thalassemia are frequently deficient in key micronutrients. Attempts to correct these inadequacies through nutritional supplementation have been met with some success, although disparities between intake and circulating levels continue to be observed. This study employed a convenience sample of 41 well-nourished transfusion dependent patients with thalassemia to identify possible mechanisms behind nutritional deficiencies. Each subject completed a Block 2005@ Food Frequency Questionnaire (FFQ), through which macro and micronutrient intake was quantified. Fasting blood was drawn to assess vitamins A, C, D, E, copper, selenium, zinc and hematologic parameters. Dietary intake was found to be inadequate compared to Institute of Medicine (IOM) recommendations for many of the fat-soluble vitamins, as well as calcium and zinc. Circulating deficiencies of vitamins C, D, copper, zinc and $\gamma$ tocopherol were also present in over $20 \%$ of patients. Many individuals who consumed an adequate dietary intake had deficient levels of circulating nutrients, which suggest alternative etiologies of nutrient excretion or loss, in addition to higher micronutrient requirements. Liver iron concentration displayed a significant negative relationship with vitamins $C(r=-0.62, p<0.001), E(r=-0.37, p=0.03)$, and zinc $(\mathrm{r}=-0.35, \mathrm{p}=0.037)$, indicating that in iron-overloaded patients, these nutrients are either endogenously consumed at higher rates or sequestered within the liver, resulting in a functional nutrient deficiency. While this study identified hepatic iron overload to be a significant cause of nutritional deficits commonly observed in patients with thalassemia, multiple etiologies are simultaneously responsible. In response to these findings, nutritional status should be monitored regularly in at-risk patients with thalassemia, and prophylactically addressed with supplementation or aggressive chelation to avoid associated co-morbidities.
\end{abstract}

Keywords: thalassemia, nutrition, vitamin C, vitamin D, iron overload, zinc, Food Frequency Questionnaire

Cite This Article: Elijah K Goldberg, Sushrita Neogi, Ashutosh Lal, Annie Higa, and Ellen Fung, "Nutritional Deficiencies Are Common in Patients with Transfusion-Dependent Thalassemia and Associated with Iron Overload.” Journal of Food and Nutrition Research, vol. 6, no. 10 (2018): 674-681. doi: 10.12691/jfnr-6-10-9.

\section{Introduction}

Depressed circulating levels of essential micronutrients such as zinc, copper, vitamin C, vitamin D, and folate have been observed previously in transfusion dependent adults with thalassemia (Thal) who consume an American diet [1]. Deficiencies may be caused by decreased dietary intake, elevated losses, or an increased endogenous requirement for key micronutrients. An increased urinary excretion of multiple minerals and transport proteins has been observed in Thal including calcium, zinc and albumin [2,3,4]. The increased renal losses of key nutrients, up to $400 \%$ above subjects without Thal, is thought to be one of the strongest predictors of mineral deficiencies [5].
Reduced total caloric intake is also frequently observed in individuals with Thal, purportedly related to small stature [6] and reduced physical activity [7]. Decreased caloric consumption may increase the risk of nutritional deficits if an individual consumes a significant amount of "empty calories", or foods with little nutritional value. When the nutritional and physiological status of 30 patients with Thal was compared to healthy controls, Thal patients presented with poor growth, lower body fat, and decreased albumin [8]. When these patients were subsequently provided a high calorie diet, after eight weeks all parameters (growth, body fat, albumin) significantly increased. Authors concluded that dietary intake in patients with Thal was not adequate to support endogenous needs for growth and immune function.

Though at least a handful of studies have investigated dietary intake or nutritional assessment via circulating 
nutrients in patients with Thal, current research is limited by a lack of literature comparing dietary intake to markers of circulating nutritional status. Additionally, many previous studies have been completed in subjects residing in developing countries, whose local diets may have contributed to a very different nutritional status than those who primarily receive their care in the United States or Europe. Therefore, the aim of this study was to quantify dietary intake, the circulating levels of key nutrients, and to identify possible mechanisms behind nutritional deficiencies in a relatively well-nourished, contemporary sample of subjects with Thal who consume a standard U.S. diet.

\section{Methods}

This study was conducted in a convenience sample of chronically transfused individuals with Thal above five years of age, who were provided treatment at the UCSF Benioff Children's Hospital Oakland (BCHO) between 2012 and 2013. All genotypes of thalassemia were included. Patients were approached by study personnel and asked if they would like to participate in the study at the time of their annual comprehensive clinic appointment. Individuals were excluded if they had comorbidities that would affect dietary intake and/or the absorption/excretion of nutrients (e.g. gastrointestinal disorders, eating disorders, renal disease), or if they were unable to document the food they typically consume. Written consent was obtained from all subjects or legal guardians, and assent from subjects 8-18 years. The protocol was approved by the Institutional Review Board at BCHO.

The Block 2005 Adult FFQ (NutritionQuest, Berkeley, CA) included 110 unique food categories, which inquired about a subject's dietary intake of single foods (e.g. “Oysters”), or more frequently about groups of similar foods (e.g., "Tuna, Tuna Salad, Tuna Casserole”). Subjects described their intake as consuming certain foods "never”, "a few times per year”, “once per month”, "2-3 times per month”, “once per week”, "2 times per week", "3-4 times per week", "5-6 times per week”, or "every day”. Portion size was ascertained using a visual guide provided as a separate handout to subjects. Additional questions focused on vitamin/mineral supplement usage. Food frequency questionnaires were analyzed by NutritionQuest and individualized nutritional intake was provided for 90 macro and micronutrients, accounting for both dietary intake and supplementation. Specific nutrient intake was then compared to the Institute of Medicine (IOM) nutritional recommendations based on age and gender (IOM, 1997-2011, Dietary Reference Intakes).

Medical record information pertaining to thalassemia genotype, presence of comorbidities (e.g. diabetes, cardiomyopathies, thyroid diseases), and pertinent laboratory values were collected from the subject's electronic medical record. Blood was drawn as part of an annual nutrition panel in all subject's pre-transfusion, within \pm 6 months of the FFQ. The nutrition panel (vitamin E, C, copper, zinc, selenium, ceruloplasmin) and glucose was drawn fasted. Labs were analyzed by the QUEST diagnostic laboratory (Valencia, CA). Three individuals who had only their comprehensive clinic visit at BCHO had fasting labs drawn at their home institutions. Liver iron concentration (LIC) was assessed by Superconducting Quantum Interference
Device (SQUID) within six months of FFQ completion in 26 of the 36 individuals with SQUID data (72\%). Body composition was determined by whole body DXA scan (Hologic, Discovery A, Medford MA).

\subsection{Calculated Variables and Definitions}

In the analysis, adolescents were defined as individuals at or below 18 years of age, for consistency with the IOM definitions. The intake of individual nutrients was quantified and defined as inadequate if less than the estimated average requirement (EAR) for age and sex. EAR is defined by the IOM as the intake level for a nutrient at which the needs of $50 \%$ of the population will be met [9]. The EAR is typically used to assess the adequacy of intake in groups [10,11]. Estimated energy requirement (EER) was calculated for each individual using their age, sex, height, and weight according to Mifflin et al [12] for adults, and Schofield [13] for adolescents. Given our previous finding that the majority of subjects with thalassemia participate in limited physical activity outside the home, EER is estimated based on a sedentary lifestyle activity coefficient of 1.0. Percentage of EER was calculated as \%EER $=(\mathrm{kcal} / \mathrm{EER}) * 100$. Body mass index was calculated as kilograms of body weight per height in square meters. Lean mass and fat mass were abstracted from whole body DXA scans, and Z-scores calculated from Kelly et al. [14] To obtain a more accurate assessment of serum ferritin, an "average ferritin" was calculated in this study, generated by averaging all serum ferritin lab values drawn six months prior to completion of the FFQ. Dietary intake was compared to a reference data set previously published by Subar AF, 2001, which included $n=226$ males and $n=238$ females, all of whom completed the 1995 version of the Block Food Frequency Questionnaire [15].

\subsection{Analyses}

Variables were initially visually represented via scatterplot to look for outliers, then summarized (means \pm $\mathrm{SD}, \%)$. Chi-squared was used to describe differences in categorical data such as gender, ethnicity, or proportions of subjects. Fisher's exact follow-up test was utilized when chi-squared tables included values with small or zero values (e.g. race, genotype). T-tests were used to assess differences by gender, age group, and supplementation status in continuous variables. Pearson's coefficients were used for correlations. Multiple linear regression models were used to explore variables related to circulating nutrient levels including nutrient intake, LIC, race, age, and gender. Analysis of variance for multiple comparisons was performed to assess differences between circulating levels of nutrients and the dietary intake of those same nutrients. All tests were two-tailed with a threshold for significance of $\mathrm{p}<0.05$. Data was analyzed using STATA v15 (College Station, TX).

\section{Results}

Forty-one patients with transfusion dependent thalassemia (28.3 \pm 10.8 years, range: 10-54 years, 10 adolescents) 
participated in this study (Table 1). As evidenced by an elevated liver iron concentration $(1.6 \pm 1.26 \mathrm{mg} \mathrm{Fe} / \mathrm{g}$ dry weight), the majority of our subjects $(n=25)$ were iron overloaded, as defined by a LIC value of $\geq 0.6 \mathrm{mg} \mathrm{Fe} / \mathrm{g}$ dry weight. As expected, males were taller but not heavier than females in this cohort, nor did lean mass or fat mass differ by gender. Thal subjects had similar lean and fat mass for age compared to reference data. Adults were heavier and taller than adolescents, but they did not have a statistically greater total body iron burden compared to the adolescent cohort (data not shown). Lean and fat mass Z-scores were also not different between adolescents and adults.

Table 1. Demographic and Body Composition Characteristics of Subjects with Thalassemia

\begin{tabular}{|c|c|c|c|c|}
\hline & Total & Male & Female & p-value ${ }^{\mathrm{a}}$ \\
\hline No. of subjects & 41 & 20 & 21 & \\
\hline Age (years) ${ }^{b}$ & $28.3 \pm 10.8$ & $26.7 \pm 9.7$ & $29.9 \pm 11.8$ & NS \\
\hline Adolescents (\%) & 24.4 & $10,(50 \%)$ & $10,(50 \%)$ & \\
\hline Height $(\mathrm{cm})$ & $158.7 \pm 11.0$ & $162.4 \pm 12.8$ & $155.2 \pm 7.7$ & 0.03 \\
\hline Weight (kg) & $56.4 \pm 16.5$ & $56.2 \pm 15.0$ & $56.7 \pm 18.1$ & NS \\
\hline $\operatorname{BMI}^{\mathrm{c}}\left(\mathrm{kg} / \mathrm{m}^{2}\right)$ & $22.1 \pm 5.2$ & $20.1 \pm 3.9$ & $23.3 \pm 6.1$ & NS \\
\hline Race (\% of total) & & & & NS \\
\hline Caucasian & 12.2 & 0.0 & 23.8 & \\
\hline Asian & 56.1 & 65.0 & 47.6 & \\
\hline South Asian & 17.1 & 20.0 & 14.3 & \\
\hline Middle Eastern & 14.6 & 15.0 & 14.3 & \\
\hline Thalassemia Classification (\% of total) & & & & NS \\
\hline ß-Thal & 83.0 & 80.0 & 85.7 & \\
\hline E- $\beta$ Thal & 12.0 & 15 & 9.5 & \\
\hline$\alpha$ Thal & 5.0 & 5.0 & 4.8 & \\
\hline Liver iron concentration $^{\mathrm{e}}$ (mg Fe/g dry tissue) & $1.6 \pm 1.26$ & $1.3 \pm 1.0$ & $1.4 \pm 1.3$ & NS \\
\hline Lean Mass Z-Score ${ }^{\mathrm{f}}$ & $0.13 \pm 0.15$ & $0.12 \pm 0.08$ & $0.14 \pm 0.20$ & NS \\
\hline Fat Mass Z-Score ${ }^{f}$ & $0.24 \pm 0.75$ & $0.10 \pm 0.80$ & $0.36 \pm 0.71$ & NS \\
\hline
\end{tabular}

${ }^{\mathrm{a}, \mathrm{b}}$ For continuous variables, data is presented as mean $\pm \mathrm{SD}$, and p-values are generated from analysis of variance for difference between males and females. For categorical variables, data is presented as a \% of total subject's population p-values are from chi-squared with Fisher's exact follow-up test. P-values were considered statistically significant at a level of $\mathrm{p}<0.05$.

${ }^{\mathrm{c}}$ BMI: body mass index, calculated as $\mathrm{kg} / \mathrm{m}^{2}$.

${ }^{\mathrm{d}}$ Includes subjects with $\mathrm{HbH} / \mathrm{CS}=$ hemoglobin $\mathrm{H} /$ Constant Spring.

${ }^{\mathrm{e}}$ Liver iron concentration was determined by superconducting quantum interference device (SQUID). The LIC measured in mcg/g wet-liver-weight was converted to dry-liver-weight using the formula mcg/g wet-liver-weight x 6/1000 = mg/g dry-liver-weight

${ }_{\mathrm{f}}^{\mathrm{f}}$ Lean \& Fat Mass obtained from DXA; Z-scores calculated from National Health and Nutrition Examination Survey Reference Data 2008: Kelly TL, Wilson KE, Heymsfield SB. Dual energy X-Ray absorptiometry body composition reference values from NHANES. PLoS One. 2009; 4(9): e7038.

Table 2. Dietary Intake and Energy Requirements in Subjects with Thalassemia Compared to Reference Data

\begin{tabular}{|c|c|c|c|c|c|c|}
\hline Daily Dietary Intake & Total & Male & Male Reference $^{\mathrm{b}}$ & Female & Female Reference $^{\mathrm{b}}$ & p-value ${ }^{a}$ \\
\hline No. of Subjects & 41 & 20 & 226 & 21 & 238 & \\
\hline Calories $(\mathrm{kcal})^{\mathrm{c}}$ & $1555 \pm 835$ & $1712 \pm 984$ & $2175 \pm 697$ & $1398 \pm 641$ & $1632 \pm 557$ & NS \\
\hline$\%$ of EER ${ }^{\mathrm{d}}$ & $103.8 \pm 58.7$ & $110.8 \pm 64.8$ & & $97.2 \pm 63.0$ & & NS \\
\hline Protein (g) & $65.4 \pm 45.9$ & $74.4 \pm 53.8$ & $89.5 \pm 32.4$ & $56.3 \pm 35.4$ & $66.6 \pm 23.9$ & NS \\
\hline Carbohydrates (g) & $172.7 \pm 96.1$ & $194.2 \pm 117.5$ & $258.1 \pm 99.2$ & $151.1 \pm 64.5$ & $195.4 \pm 76.4$ & NS \\
\hline Fats (g) & $68.4 \pm 40.7$ & $71.3 \pm 44.5$ & $81.1 \pm 31.0$ & $65.5 \pm 37.3$ & $62.6 \pm 26.0$ & NS \\
\hline Saturated Fats (g) & $20.7 \pm 11.3$ & $21.7 \pm 11.7$ & $28.3 \pm 11.8$ & $19.72 \pm 11.1$ & $21.7 \pm 9.6$ & NS \\
\hline Trans Fats (g) & $2.4 \pm 1.8$ & $2.7 \pm 1.7$ & & $2.1 \pm 1.9$ & & NS \\
\hline Calories from protein (\%) & $16.4 \pm 3.6$ & $17.3 \pm 3.9$ & 16.6 & $15.6 \pm 3.1$ & 16.4 & NS \\
\hline Calories from carbohydrates (\%) & $45.0 \pm 8.5$ & $45.3 \pm 8.7$ & 47.2 & $44.6 \pm 8.5$ & 48.0 & NS \\
\hline Calories from sweets (\%) & $11.5 \pm 10.2$ & $11.8 \pm 10.8$ & & $11.3 \pm 9.8$ & & NS \\
\hline Calories from fats (\%) & $39.5 \pm 6.6$ & $37.7 \pm 6.6$ & 34.0 & $41.4 \pm 6.1$ & 34.3 & 0.07 \\
\hline Copper (mg) & $1.2 \pm 1.0$ & $1.5 \pm 1.4$ & & $1.0 \pm 0.41$ & & NS \\
\hline Iron (mg) & $11.3 \pm 6.8$ & $12.7 \pm 7.8$ & $16.7 \pm 6.2$ & $9.9 \pm 5.4$ & $12.1 \pm 4.6$ & NS \\
\hline Selenium $(\mu \mathrm{g})$ & $82.9 \pm 46.7$ & $92.1 \pm 49.5$ & & $73.7 \pm 43.0$ & & NS \\
\hline Zinc (mg) & $9.2 \pm 5.3$ & $10.7 \pm 6.0$ & $13.0 \pm 5.8$ & $7.7 \pm 4.1$ & $9.4 \pm 3.8$ & 0.07 \\
\hline Vitamin C (mg) & $90.3 \pm 72.5$ & $94.5 \pm 85.9$ & $115.1 \pm 67.2$ & $86.0 \pm 58.2$ & $102.1 \pm 60.0$ & NS \\
\hline Vitamin D $\left(\mathrm{IU}^{\mathrm{e}}\right)$ & $102.6 \pm 83.4$ & $116.0 \pm 91.1$ & & $89.3 \pm 74.8$ & & NS \\
\hline Vitamin $E^{\mathrm{f}}$ (mg) & $7.27 \pm 4.88$ & $7.5 \pm 5.2$ & & $7.1 \pm 4.7$ & & NS \\
\hline Folate $(\mu \mathrm{g})$ & $121.0 \pm 99.1$ & $141.9 \pm 84.9$ & & $102.5 \pm 109.3$ & & NS \\
\hline
\end{tabular}

${ }^{\mathrm{a}, \mathrm{c}}$ For continuous variables, the data is presented as mean \pm SD. p-values are calculated using t-test statistical analysis for differences between non control males and females; $\mathrm{p}$-values were considered statistically significant at a level of $\mathrm{p}<0.05$.

${ }^{\mathrm{b}}$ Reference data derived from Subar AF, Thompson FE, Kipnis V, Midthune D, Hurwitz P, McNutt S, et al. Comparative validation of the Block, Willett, and National Cancer Institute food frequency questionnaires: the Eating at America's Table Study. Am J Epidemiol. $2001 ; 154(12)$ : 1089-99.

${ }^{\mathrm{d}}$ EER: Estimated Energy Requirement calculated using equations of Mifflin et al (1990) for adults, and Schofield's 1985 equation for adolescents.

${ }^{\mathrm{e}} \mathrm{IU}=$ International Unit, as determined by the World Health Organization for an individual nutrient.

${ }^{\mathrm{f}}$ Dietary intake of vitamin E, prior to absorption, is referred to as a tocopherol equivalent. 


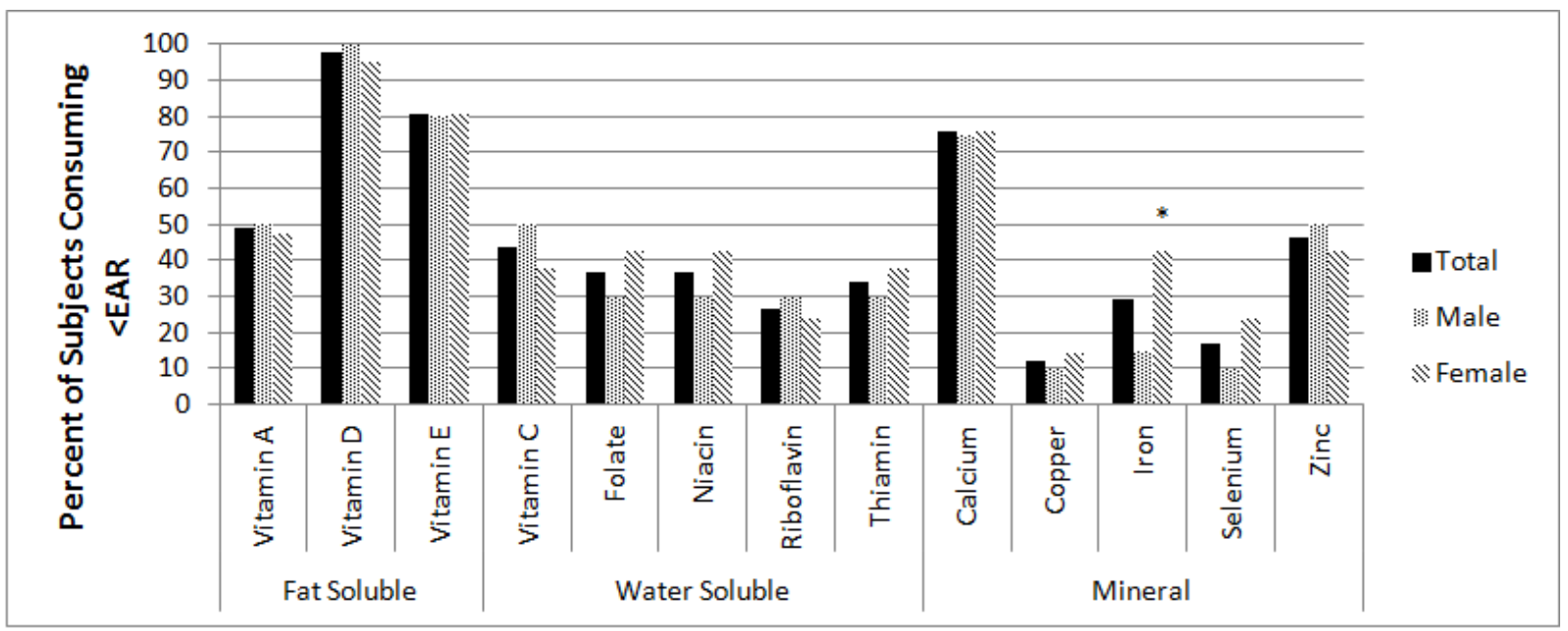

* denotes significant differences in nutrient intake between genders by $\mathrm{p}<0.05$. Male subjects are represented by the dotted bars, Females by the striped bars, and the entire cohort by the filled bars.

Figure 1. Micronutrient Inadequacies in Subjects with Thalassemia Assessed by Food Frequency Questionnaire

On average, most subjects were meeting their estimated caloric requirements as evidenced by \%EER not deviating from $100 \%$ (Table 2). Overall, $24 \%$ of subjects consumed $\geq 120 \%$ of their EER, while $39 \%$ consumed $\leq 80 \%$ of their EER. There were no differences in these estimations by gender or age group. Female subjects also had a significantly lower caloric contribution from carbohydrates in comparison to the reference cohort $(p<0.05)$. Vitamin D was most commonly consumed in inadequate amounts; forty out of forty-one (97\%) subjects did not ingest adequate dietary vitamin D. Vitamins A, E, calcium and zinc, were also found to be consumed in limited amounts, each with at least $50 \%$ of the cohort consuming less than the EAR (Figure 1). The only nutrients in which $>80 \%$ of subjects consumed adequate amounts were copper and selenium. Age group differences in dietary insufficiency were statistically significant for vitamins A, C, and calcium (each $\mathrm{p}<0.05$ ). Adolescents also consumed a higher percentage of their total calories as carbohydrates and ate fewer trans fats compared to adults (both $\mathrm{p}<0.05$, data not shown).

Blood was drawn within $25 \pm 124$ days of the FFQ. There were no overt signs of protein deficiency; albumin was within normal range for $98 \%(n=40)$ of our cohort. Typical pre-transfusion hematological indices were observed for these transfusion dependent subjects with thalassemia: depressed $\mathrm{Hb}, \mathrm{HCT}$ and elevated serum ferritin (Table 3). Five individuals in our cohort were diagnosed with diabetes prior to study entry, which elevated the mean blood glucose. Alkaline phosphatase tended to be lower in adolescents $(\mathrm{p}=0.06)$, but vitamin $\mathrm{D}$ $(\mathrm{p}=0.08)$ and selenium $(\mathrm{p}=0.07)$ higher in comparison to adults (data not shown). Only serum copper and its transport protein, ceruloplasmin, showed a gender bias with significantly more males deficient $(\mathrm{p}<0.05)$.

Table 3. Hematological, Biochemical and Nutritional Parameters in Subjects with Thalassemia by Gender

\begin{tabular}{|l|c|c|c|c|}
\hline Serum Values & Total & \% Abnormal ${ }^{\mathrm{a}}$ & Male & Female \\
\hline No. of Subjects & 41 & & 20 & 21 \\
\hline Hemoglobin $(\mathrm{g} / \mathrm{dL})^{\mathrm{c}}{ }^{\mathrm{a}}$ & $10.9 \pm 1.5$ & $76 \%$ & $11.0 \pm 1.9$ & $10.9 \pm 1.1$ \\
\hline Hematocrit $(\%)$ & $32.1 \pm 4.3$ & $68 \%$ & $32.3 \pm 5.1$ & $32.0 \pm 3.3$ \\
\hline Albumin $(\mathrm{g} / \mathrm{dL})$ & $4.5 \pm 0.90$ & $3 \%$ & $4.5 \pm 0.49$ & $4.6 \pm 1.2$ \\
\hline Glucose $(\mathrm{mg} / \mathrm{dL})$ & $111.1 \pm 54.6$ & $35 \%{ }^{\mathrm{d}}$ & $119.1 \pm 66.7$ & $103.5 \pm 40.3$ \\
\hline Alkaline Phosphatase (IU/L) & $120 \pm 57$ & $0 \%$ & $121.3 \pm 58.3$ & 120.3 \\
\hline Alanine Transferase $(\mathrm{IU} / \mathrm{L})$ & $49.6 \pm 39.2$ & $33 \%$ & $48.5 \pm 41.0$ & $50.8 \pm 38.3$ \\
\hline Serum ferritin $\left(\mathrm{ng} / \mathrm{mL}^{\mathrm{g}}\right)$ & $1942 \pm 1983$ & $100 \%$ & $2080 \pm 2075$ & $1916 \pm 2510$ \\
\hline Zinc $(\mu \mathrm{g} / \mathrm{dL})$ & $76.1 \pm 16.2$ & $41 \%$ & $77.6 \pm 17.8$ & $74.3 \pm 14.4$ \\
\hline Copper $(\mu \mathrm{g} / \mathrm{dL})^{\mathrm{b}}$ & $92.7 \pm 31.0$ & $21 \%$ & $78.2 \pm 24.0$ & $108.1 \pm 30.6$ \\
\hline Ceruloplasmin $(\mathrm{mg} / \mathrm{dL})$ & $24.0 \pm 6.18$ & $6 \%$ & $20.0 \pm 2.8$ & $27.7 \pm 6.2$ \\
\hline Selenium $(\mu \mathrm{m} / \mathrm{L})$ & $127 \pm 29$ & $0 \%$ & $124.2 \pm 23.2$ & $130.6 \pm 34.3$ \\
\hline Vitamin D $(\mathrm{ng} / \mathrm{mL})$ & $36.1 \pm 14.2$ & $35 \%$ & $34.3 \pm 14.3$ & $38.0 \pm 14.1$ \\
\hline Vitamin C $(\mathrm{mg} / \mathrm{dL})$ & $0.93 \pm 0.56$ & $19 \%$ & $0.88 \pm 0.43$ & $0.99 \pm 0.68$ \\
\hline$\alpha$ Tocopherol $(\mathrm{mg} / \mathrm{L})$ & $8.7 \pm 3.3$ & $0 \%$ & $8.2 \pm 3.4$ & $9.2 \pm 3.1$ \\
\hline$\gamma$ Tocopherol $(\mathrm{mg} / \mathrm{L})$ & $2.3 \pm 1.2$ & $97 \%$ & $2.3 \pm 1.1$ & $2.3 \pm 1.4$ \\
\hline
\end{tabular}

${ }^{\mathrm{a}}$ Using reference guidelines published by the Institutes of Medicine (IOM).

${ }^{\mathrm{b}}$ Gender differences in circulating copper were determined to be significant $(\mathrm{p}<0.02)$. Significance was determined using chi-squared with Fisher's exact test.

${ }^{\mathrm{c}}$ Values are presented as Mean $\pm \mathrm{SD}=$ standard deviation.

${ }^{\mathrm{d}}$ Percent of subjects with a glucose that is elevated, as defined by glucose $>100 \mathrm{mg} / \mathrm{dL}$ fasting. Of note, 5 enrolled subjects were diagnosed with diabetes prior to study entry.

${ }^{\mathrm{e}} \mathrm{IU}=$ International Unit, as determined by the World Health Organization for an individual nutrient.

${ }^{\mathrm{f} S e r u m}$ Ferritin is the average of all ferritin values drawn within the six months prior to completion of the Block Food Frequency.

${ }^{\mathrm{g}} \mathrm{To}$ convert $\mathrm{ng} / \mathrm{mL}$ ferritin to $\mathrm{pmol} / \mathrm{L}$, multiply $\mathrm{ng} / \mathrm{mL}$ by 2.247 . To convert $\mathrm{pmol} / \mathrm{L}$ ferritin to $\mathrm{ng} / \mathrm{mL}$, multiply pmol/L by 0.445 . Ferritin of 1,000 $\mathrm{ng} / \mathrm{mL}=2247 \mathrm{pmol} / \mathrm{L}$. 
Few relationships were observed between circulating levels of nutrients and dietary intake. When examining the whole subject cohort, significant (though weak) associations were observed between serum and dietary intake of $\alpha$-tocopherol $(\mathrm{r}=0.34, \mathrm{p}<0.05)$ and selenium $(\mathrm{r}=0.34, \mathrm{p}<0.05)$. No significant associations were observed between serum nutrient levels and dietary intake

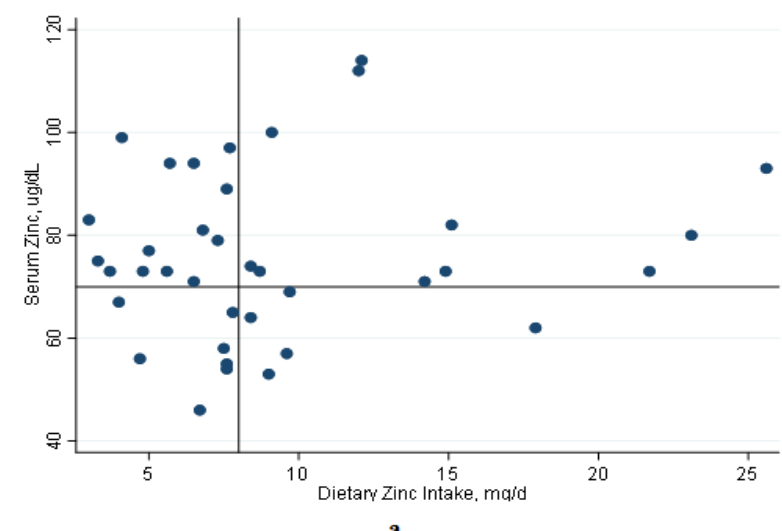

$41 \%$ of all subjects had low serum zinc $(<70 \mathrm{ug} / \mathrm{dL})$. Half of those $(50 \%)$ with low plasma zinc also had low dietary zinc intake $(<8 \mathrm{mg} /$ day)

Vertical line represents recommended dietary intake for females $>8$ years $(8 \mathrm{mg} /$ day). Horizontal line represents hypozincemia or low serum zinc concentration $(<70 \mathrm{ug} / \mathrm{dL})$.

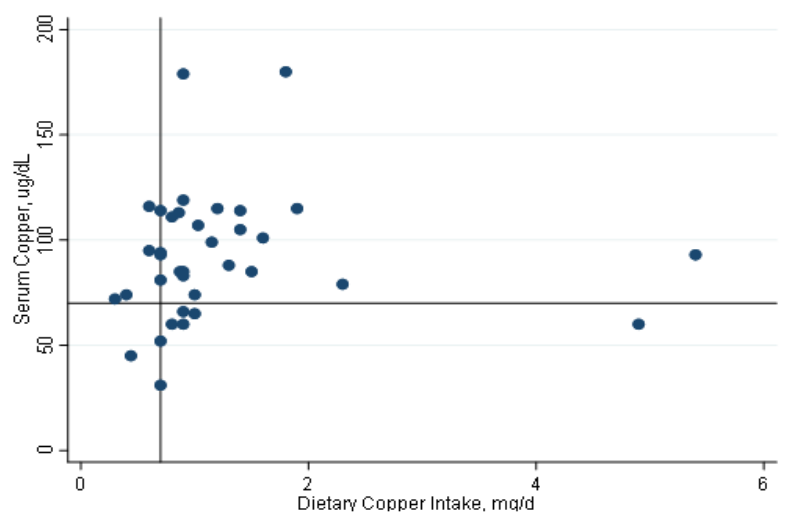

b.

8 individuals ( $21 \%$ ) of our cohort had low serum copper $(<70 \mathrm{ug} / \mathrm{dL})$ Of that group, only one (12.5\%) had low dietary copper intake $(0.7 \mathrm{mg} / \mathrm{d})$. Vertical line represents recommended dietary intake of copper for males and females $>19$ years $(0.7 \mathrm{mg} /$ day $)$. Horizontal line represents hypocupremia $(<70 \mathrm{ug} / \mathrm{dL})$.

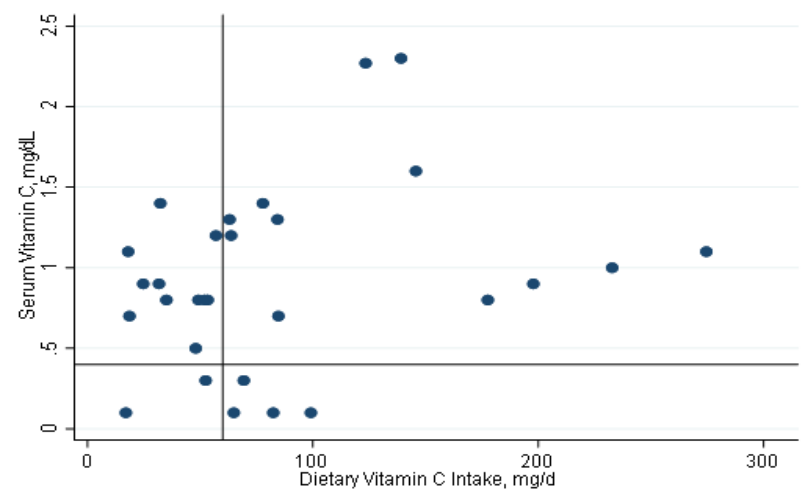

6 subjects (19\%) of our cohort presented with depressed serum vitamin C $(<0.4 \mathrm{mg} / \mathrm{dL})$. Of these individuals, $4(66 \%)$ also had inadequate dietary intake ( $<60 \mathrm{mg} / \mathrm{d})$. Vertical line represents recommended dietary intake of vitamin $\mathrm{C}$ for females $>19$ years $(60 \mathrm{mg} /$ day). Horizontal line represents ascorbate deficiency $(0.4 \mathrm{mg} / \mathrm{dL})$.

Figure 2a,b,c. Serum Zinc, Copper, and Vitamin C in Comparison to Dietary Intake in Subjects with Thalassemia of vitamin $\mathrm{D}$, copper or zinc.

28 individuals (70\%) in our cohort reported taking a multivitamin or supplement daily. The use of a supplement did not significantly impact circulating nutrients, or the relationships between intake and circulating nutrients, apart from vitamin $C$, where $\mathrm{R}^{2}$ rose slightly from 0.07 to 0.19 ( $\mathrm{p}=\mathrm{NS}$ vs $\mathrm{p}<0.032$ with supplementation).

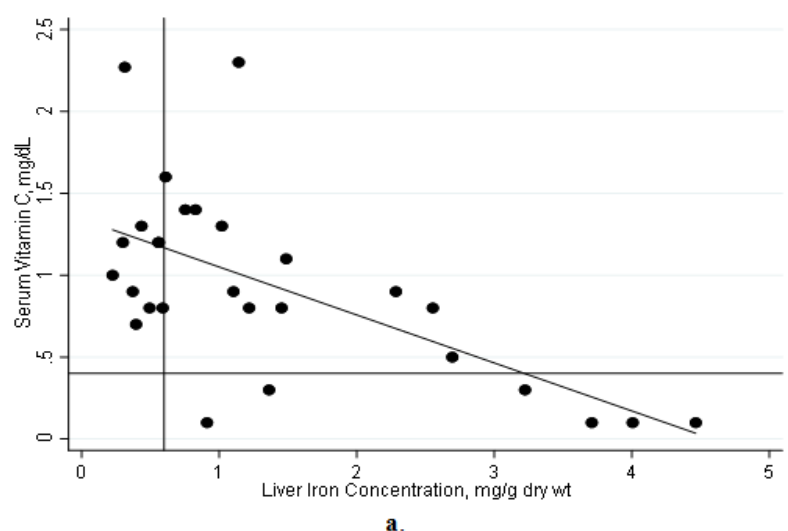

$19 \%$ of patients have low circulating vitamin C levels $(<0.4 \mathrm{mg} / \mathrm{dL})$ A significant inverse correlation was observed between liver iron concentration and vitamin $\mathrm{C}(\mathrm{r}=-0.62, \mathrm{p}<0.001)$

Horizontal line represents ascorbate deficiency $(0.4 \mathrm{ug} / \mathrm{dL})$, Vertical line indicates iron overload $(\geq 0.6 \mathrm{mg} \mathrm{Fe} / \mathrm{g}$ dry wt)

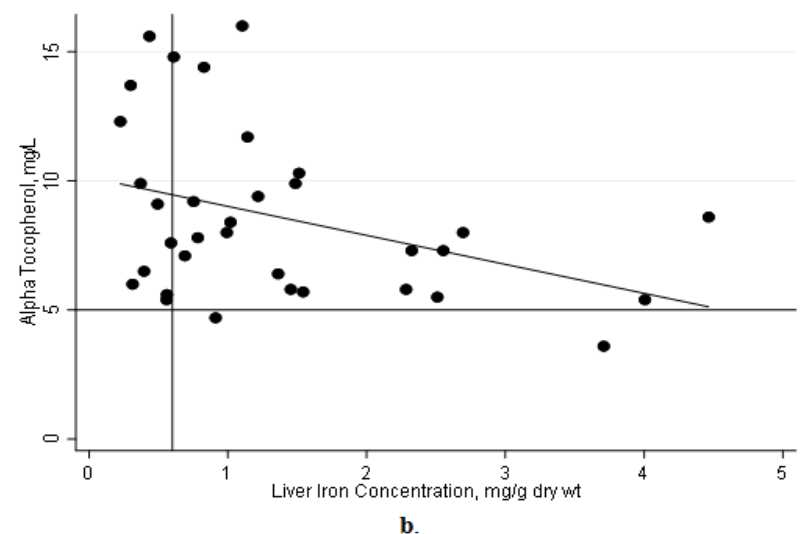

Low alpha-tocopherol $(<5 \mathrm{mg} / \mathrm{L})$ is uncommon $(\mathrm{n}=2,5 \%$ of cohort), though a significant inverse correlation was observed between liver iron concentration \& alpha-tocopherol $(\mathrm{r}=-0.37, \mathrm{p}=0.03)$. Horizontal line indicates low alpha-tocopherol $(<5 \mathrm{mg} / \mathrm{L})$. Vertical line indicates iron overload $(\geq 0.6 \mathrm{mg} \mathrm{Fe} / \mathrm{g}$ dry wt)

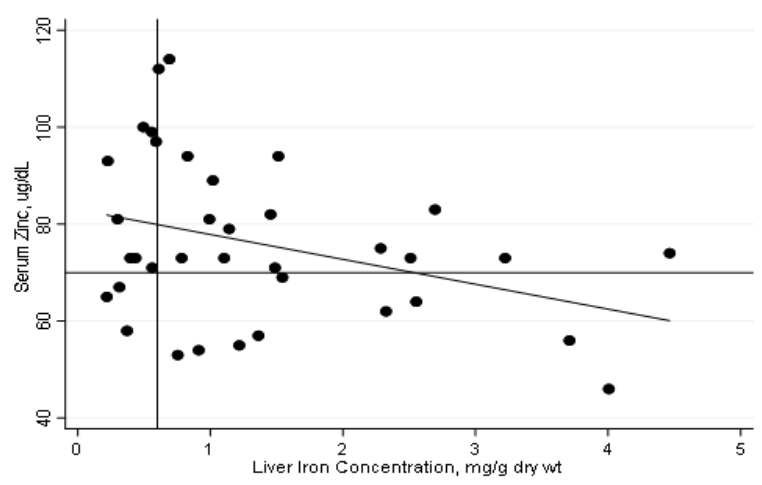
c.

Zinc deficiency is common ( $<70 \mathrm{ug} / \mathrm{dL}, 41 \%$ ), and a significant inverse correlation was observed between liver iron concentration \& serum zinc $(\mathrm{r}=-0.35, \mathrm{p}=0.037)$. Vertical line indicates iron overload $(\geq 0.6 \mathrm{mg} \mathrm{Fe} / \mathrm{g}$ dry wt). Horizontal line represents hypozincemia or low serum zinc concentration $(<70 \mathrm{ug} / \mathrm{dL})$.

Figure 3a,b,c. Vitamin C, E and Zinc Display Significant Negative Relationships with Liver Iron Concentration in Transfusion Dependent Patients with Thalassemia 
Fifty-four percent $(n=21)$ of our cohort consumed what is presumed to be an adequate amount of dietary zinc, but nearly half of those subjects $(38 \%, n=8)$ had low serum zinc (Figure 2a). Similarly, $87 \%(n=33)$ of subjects consumed adequate dietary copper, though $27 \%(n=7)$ of those individuals had low serum copper; moreover 58\% $(n=18)$ of subjects consumed adequate vitamin C (Figure 2b), but $22 \%(n=4)$ displayed depressed serum ascorbate (Figure 2c)

Using multiple linear regression analysis, vitamin $\mathrm{C}$ was negatively associated with liver iron concentration (LIC) even after controlling for age, gender, lean mass Z-score and dietary iron intake (Figure 3) $(r=-0.66$, $\left.\mathrm{R}^{2}=0.43, \mathrm{p}<0.001\right)$. Serum $\alpha$-tocopherol $\left(\mathrm{r}=-0.37, \mathrm{R}^{2}=0.14\right.$, $\mathrm{p}=0.029)$ and serum zinc also correlated negatively with LIC $\left(r=-0.35, \mathrm{R}^{2}=0.12, \mathrm{p}<0.05\right)$. Neither age nor gender were significant covariates in the relationship between zinc, $\alpha$-tocopherol, and LIC.

\section{Discussion}

In this contemporary cohort of U.S. based, relatively well-nourished, transfusion dependent patients with thalassemia, nutritional deficiencies still exist: $40 \%$ of our subjects had reduced serum zinc, 35\% had insufficient vitamin D, and close to $20 \%$ had low copper and vitamin C. Many individuals in this cohort consumed what is considered adequate dietary intake yet had deficient levels of circulating nutrients. Moreover, supplementation had a weak effect on the relationship between circulating nutrients and intake, suggesting alternative etiologies for nutritional deficiency in thalassemia. Our findings suggest iron overload to be the strongest negative influence on circulating micronutrients, namely vitamin $\mathrm{C}$, E, and zinc.

Nutritional assessment is often determined solely through circulating levels. For type I nutrients, specific deficiency signs and symptoms (e.g. scurvy) are the result of decreased tissue concentrations (e.g. low serum ascorbate, Golden 1995) [16]. It is presumed that if serum concentrations are reduced, dietary intake is similarly inadequate. This study indicates that these assumptions may not be valid for individuals with Thal. While we were unable to identify statistical associations between dietary inadequacy and decreased circulating nutrient concentrations-possibly due to a limited sample size-numerical observations of dietary and circulating insufficiencies imply otherwise. These discrepancies communicate an increased nutritional requirement in thalassemia; for patients with Thal, the EAR for zinc should be set at $>10 \mathrm{mg} / \mathrm{d}$, or $25 \%$ higher than general population; copper at $1 \mathrm{mg} / \mathrm{d}$, or $42 \%$ higher than general population; vitamin C at $100 \mathrm{mg} / \mathrm{d}$, or $33 \%$ higher than the EAR for healthy individuals. Alternatively, disparities between intake and serum nutrients could reflect poor dietary assessment techniques, insensitivity of the marker to nutritional status, or rapid endogenous consumption or excretion.

In healthy subjects without thalassemia, there has been significant research into relationships between dietary intake and circulating levels of micronutrients. This information forms the basis for dietary intake recommendations in healthy populations, in order to maintain circulating nutrient levels within a specific range. Artacho et al (1997)
[17] and Neggers et al (1997) [18] observed positive relationships between oral zinc intake and plasma zinc in a healthy cohorts. Similar correlations in healthy individuals have been observed in other essential nutrients including vitamin A [19], C [20], D [21], and E [19]. Unfortunately, little research has been conducted in patients with thalassemia to explore the etiologies behind nutritional insufficiencies. Previous studies have shown that stunted growth and slow pubertal development are correlated with suboptimal nutritional intake [22]. A 2001 study found that young Italian men with Thal who presented with delays in pubertal development also had poor overall nutritional status [23]. Two other groups showed that introducing nutritional support to young children with Thal significantly improves markers of immune function and overall growth [24,25]. These findings suggest three things: 1) that some patients with Thal are not receiving adequate nutritional support for optimal growth, development and immune function, 2) that many patients with Thal have an increased requirement for micronutrients, and 3) nutritional support may improve health outcomes by promoting nutrient balance.

The necessity of supplementation in patients with Thal has been primarily indicated by several longitudinal studies which have proven that early supplementation of zinc and vitamin D has resulted in increased stature, bone outcomes, cardiac function, and glucose sensitivity in patients with Thal $[26,27,28]$. The results of the present study, which indicate nearly $100 \%$ of subjects enrolled consumed inadequate vitamin D-with over a third presenting with depressed circulating levels-illustrates this point. However, in our analysis, daily supplementation regimens only contributed to improving nutritional status for vitamin C. Total oral intake, including supplementation, was not noticeably different from intake without supplementation-likely due to multivitamins containing insufficient amounts of micronutrients or poor adherence to supplementation in patients with Thal. Of interest, we previously observed that the implementation of a high dose (50,000 IU) vitamin D3 supplement at time of transfusion has been shown to improve vitamin D status [29].

Vitamin C, an antioxidant consumed in oxidative stress environments, has previously been reported to be low in iron-loaded patients with Thal [30]. Several investigators have found that vitamin $C$ supplementation in Thal may increase chelator efficacy of iron removal [31]. We observed that vitamin $\mathrm{C}$ was negatively correlated with liver iron concentration, suggesting that patients with iron overload are at greater risk for vitamin C deficiency. This deficiency may contribute to harmful functional outcomes and chelator inefficiency. This relationship has also been identified in Vitamin E, wherein the vitamin is consumed or otherwise utilized to counter the oxidative stress induced by severe iron overload [32,33]. Oral supplementation of vitamin $\mathrm{C}$ and vitamin $\mathrm{E}$ should be considered for those patients with iron overload, though ascorbate administration should be carefully monitored in relation to chelator type and dosage.

While our study does not include data on chelation, we speculate that due to iron's molecular similarity to zinc and copper, it is likely that these nutrients may be chelated instead of, or along with, iron, especially at low LIC 
values. Compounded with the results of this study, this hypothesis implies that both high and low iron levels increase the risk of nutrient deficiency in Thal. In addition to vitamin $\mathrm{C}$, zinc levels also have a negative relationship with liver iron concentration. In 1991, researchers found that subjects with hereditary hemochromatosis who presented with significant iron overload sequestered zinc in the liver [34]. We hypothesize that the same phenomenon is occurring in subjects with Thal--iron overload increases hepatic metallothionein concentrations which bind zinc, leading to sequestration. This may produce negative outcomes such as functional zinc deficiency, because zinc is bound in the liver rather than available in circulation. This may also account for a portion of the disconnect we witnessed between dietary and circulating zinc.

While this study has provided a crucial base of information regarding nutritional assessment in thalassemia, there are limitations. The two primary limitations of our data are the use of Block FFQ, and our cohort size. The food frequency questionnaire never fully captures daily dietary variation of an individual, nor is it able to address cultural dietary complexity. However, the FFQ has been shown to accurately quantitate average intake over a long period of time (6-12 months); prior research has indicated that FFQ's have a correlation value of $0.4-0.7$ with actual nutrient intake [35]. Furthermore, due to a limited sample size and the variability between patients, our data may not be fully generalizable to all individuals with thalassemia.

\section{Conclusion}

Dietary intake guidelines should be reassessed and possibly increased for patients with Thal. LIC plays a key role in circulating nutrient levels; LIC shows a significant negative correlation with vitamin $\mathrm{C}, \alpha$-tocopherol, and zinc, suggesting that certain proteins in the liver may serve to "trap" nutrients in iron overloaded conditions, creating a functional nutrient deficiency. Urinary losses and chelator induced excretion of minerals may also play a role in functional nutritional deficiencies. Given the number of comorbidities that are associated with nutritional inadequacies in Thal, it is imperative that future research focus on exploring the etiologies of nutrient excretion and deficiency in Thal, and for care providers to consider early nutritional supplementation for at-risk patients.

\section{Acknowledgements}

The authors would like to thank the patients with Thal at BCHO who participated in this study, Lisa Calvelli for her assistance in performing DXA scans for the assessment of body composition, and Dr. Amy Subar for providing the reference data used in this study. This study was supported in part by a grant from the NIH R25 HL125451.

\section{Statement of Competing Interests}

The authors have no competing interests.

\section{Abbreviations}

\author{
DXA —Dual Energy X-Ray Absorptiometry \\ Thal - Thalassemia \\ LIC - Liver Iron Concentration \\ EAR —Estimated Average Requirement \\ IOM - Institute of Medicine \\ FFQ —Food Frequency Questionnaire
}

\section{References}

[1] Claster S, Wood JC, Noetzli L, Carson SM, Hofstra TC, Khanna R, et al. Nutritional deficiencies in iron overloaded patients with hemoglobinopathies. Am J Hematol. 2009; 84(6): 344-8.

[2] Quinn CT, Johnson VL, Kim HY, Trachtenberg F, Vogiatzi MG, Kwiatkowski JL, et al. Renal dysfunction in patients with thalassaemia. Br J Haematol. 2011; 153(1): 111-7.

[3] Fung EB. Nutritional deficiencies in patients with thalassemia. Ann N Y Acad Sci. 2010; 1202: 188-96.

[4] Aydinok Y, Coker C, Kavakli K, Polat A, Nisli G, Cetiner N, et al. Urinary zinc excretion and zinc status of patients with betathalassemia major. Biol Trace Elem Res. 1999; 70(2): 165-72.

[5] Uysal Z, Akar N, Kemahli S, Dincer N, Arcasoy A Desferrioxamine and urinary zinc excretion in beta-thalassemia major. Pediatr Hematol Oncol. 1993; 10(3): 257-60.

[6] Tienboon P, Sanguansermsri T, Fuchs GJ. Malnutrition and growth abnormalities in children with beta thalassemia major. Southeast Asian J Trop Med Public Health. 1996; 27(2): 356-61.

[7] Fung EB, Pinal J, Leason M. Reduced Physical Activity Patterns in Patients with Thalassemia Compared to Healthy Controls. Journal Hematology Oncology Research 2015; 2(1)7-21.

[8] Soliman AT, El-Matary W, Fattah MM, Nasr IS, El Alaily RK, Thabet MA. The effect of high-calorie diet on nutritional parameters of children with beta-thalassaemia major. Clin Nutr. 2004; 23(5): 1153-8.

[9] National Academies of Sciences, Engineering, and Medicine; Health and Medicine Division; Food and Nutrition Board; Committee on the Development of Guiding Principles for the Inclusion of Chronic Disease Endpoints in Future Dietary Reference Intakes; Oria MP, Kumanyika S, editors. Guiding Principles for Developing Dietary Reference Intakes Based on Chronic Disease. Washington (DC): National Academies Press (US); 2017 Aug 3. 2, The Current Process to Establish Dietary Reference Intakes. Available from: https://www.ncbi.nlm.nih.gov/books/NBK465020/

[10] Institute of Medicine (US) Food and Nutrition Board. Dietary Reference Intakes: A Risk Assessment Model for Establishing Upper Intake Levels for Nutrients. Washington (DC): National Academies Press (US); 1998. What are Dietary Reference Intakes? Available from: https://www.ncbi.nlm.nih.gov/books/NBK45182/

[11] Institute of Medicine (US) Subcommittee on Interpretation and Uses of Dietary Reference Intakes; Institute of Medicine (US) Standing Committee on the Scientific Evaluation of Dietary Reference Intakes. DRI Dietary Reference Intakes: Applications in Dietary Assessment. Washington (DC): National Academies Press (US); 2000. 4, Using the Estimated Average Requirement for Nutrient Assessment of Groups. Available from: https://www.ncbi.nlm.nih.gov/books/NBK222898/.

[12] Mifflin MD, St jeor ST, Hill LA, Scott BJ, Daugherty SA, Koh YO. A new predictive equation for resting energy expenditure in healthy individuals. Am J Clin Nutr. 1990; 51(2): 241-7.

[13] Schofield WN. Predicting basal metabolic rate, new standards and review of previous work. Hum Nutr Clin Nutr. 1985; 39 Suppl 1: 5-41.

[14] Kelly TL, Wilson KE, Heymsfield SB. Dual energy X-Ray absorptiometry body composition reference values from NHANES PLoS One. 2009; 4(9): e7038.

[15] Subar AF, Thompson FE, Kipnis V, Midthune D, Hurwitz P, McNutt S, et al. Comparative validation of the Block, Willett, and National Cancer Institute food frequency questionnaires: the Eating at America's Table Study. Am J Epidemiol. 2001; 154(12): 1089-99. 
[16] Golden MH. Specific deficiencies versus growth failure: type I and type II nutrients. SCN News. 1995(12): 10-4.

[17] Artacho R, Ruiz-Lopez MD, Gamez C, Puerta A, Lopez MC. Serum concentration and dietary intake of $\mathrm{Zn}$ in healthy institutionalized elderly subjects. Sci Total Environ. 1997; 205(2-3): 159-65.

[18] Neggers YH, Goldenberg RL, Tamura T, Johnston KE, Copper RL, DuBard M. Plasma and erythrocyte zinc concentrations and their relationship to dietary zinc intake and zinc supplementation during pregnancy in low-income African-American women. J Am Diet Assoc. 1997; 97(11): 1269-74.

[19] Ascherio A, Stampfer MJ, Colditz GA, Rimm EB, Litin L, Willett WC. Correlations of vitamin A and $\mathrm{E}$ intakes with the plasma concentrations of carotenoids and tocopherols among American men and women. J Nutr. 1992; 122(9): 1792-801.

[20] Vioque J, Weinbrenner T, Asensio L, Castello A, Young IS, Fletcher A. Plasma concentrations of carotenoids and vitamin C are better correlated with dietary intake in normal weight than overweight and obese elderly subjects. Br J Nutr. 2007; 97(5): 977-86.

[21] Mifflin MD, St jeor ST, Hill LA, Scott BJ, Daugherty SA, Koh YO. A new predictive equation for resting energy expenditure in healthy individuals. Am J Clin Nutr. 1990; 51(2): 241-7.

[22] Grantham-McGregor S, Powell C, Fletcher P. Stunting, severe malnutrition and mental development in young children. Eur J Clin Nutr. 1989; 43(6): 403-9.

[23] Filosa A, Di Maio S, Esposito G, De Martinis F, De Terlizzi F. Persistence of delayed adrenarche in boys with thalassemia. J Pediatr Endocrinol Metab. 2001; 14(4): 407-14.

[24] Tienboon P. Effect of nutrition support on immunity in paediatric patients with beta-thalassaemia major. Asia Pac J Clin Nutr. 2003; 12(1): 61-5.

[25] Fuchs GJ, Tienboon P, Linpisarn S, Nimsakul S, Leelapat P, Tovanabutra S, et al. Nutritional factors and thalassaemia major. Arch Dis Child. 1996; 74(3): 224-7.
[26] Arcasoy A, Cavdar A, Cin S, Erten J, Babacan E, Gozdasoglu S, et al. Effects of zinc supplementation on linear growth in betathalassemia (a new approach). Am J Hematol. 1987; 24(2): 127-36.

[27] Fung EB, Kwiatkowski JL, Huang JN, Gildengorin G, King JC, Vichinsky EP. Zinc supplementation improves bone density in patients with thalassemia: a double-blind, randomized, placebocontrolled trial. Am J Clin Nutr. 2013; 98(4): 960-71.

[28] Wood JC, Claster S, Carson S, Menteer JD, Hofstra T, Khanna R, et al. Vitamin D deficiency, cardiac iron and cardiac function in thalassaemia major. Br J Haematol. 2008; 141(6): 891-4.

[29] Fung EB, Aguilar C, Micaily I, Haines D, Lal A. Treatment of vitamin D deficiency in transfusion-dependent thalassemia. Am J Hematol. 2011; 86(10): 871-3.

[30] Shah NR, Wolff JA, Sitarz AL, Lee CK, Massa E, Diaz R. DEPLETION OF VITAMIN C IN PATIENTS WITH THALASSEMIA MAJOR. EFFECT OF VITAMIN C REPLETION ON DESFERRIOXAMINE INDUCED URINARY IRON EXCRETION. Pediatric Research. 1974; 8: 408.

[31] Elalfy MS, Saber MM, Adly AA, Ismail EA, Tarif M, Ibrahim F, et al. Role of vitamin $\mathrm{C}$ as an adjuvant therapy to different iron chelators in young beta-thalassemia major patients: efficacy and safety in relation to tissue iron overload. Eur J Haematol. 2016; 96(3): 318-26.

[32] Walter PB, Fung EB, Killilea DW, Jiang Q, Hudes M, Madden J, et al. Oxidative stress and inflammation in iron-overloaded patients with beta-thalassaemia or sickle cell disease. $\mathrm{Br} \mathrm{J}$ Haematol. 2006; 135(2): 254-63.

[33] Tesoriere L, D'Arpa D, Butera D, Allegra M, Renda D, Maggio A, et al. Oral supplements of vitamin $\mathrm{E}$ improve measures of oxidative stress in plasma and reduce oxidative damage to LDL and erythrocytes in beta-thalassemia intermedia patients. Free Radic Res. 2001; 34(5): 529-40.

[34] Adams PC, Bradley C, Frei JV. Hepatic zinc in hemochromatosis. Clin Invest Med. 1991; 14(1): 16-20.

[35] Thompson FE, Byers T. Dietary assessment resource manual. J Nutr. 1994; 124(11 Suppl): 2245S-317S. 